\title{
Safety and efficacy of alpha-I-antitrypsin augmentation therapy in the treatment of patients with alpha-I-antitrypsin deficiency
}

This article was published in the following Dove Press journal:

Biologics: Targets \& Therapy

30 April 2009

Number of times this article has been viewed

\author{
Irina Petrache' \\ Joud Hajjar' \\ Michael Campos ${ }^{2}$ \\ 'Department of Medicine, Indiana \\ University School of Medicine, \\ Indianapolis, Indiana, USA; \\ ${ }^{2}$ Department of Medicine, Division \\ of Pulmonary, Critical Care and Sleep \\ Medicine, Miller School of Medicine, \\ University of Miami, Florida, USA
}

Correspondence: Irina Petrache Indiana University, Division of Pulmonary, Allergy, Critical Care and Occupational Medicine, Van Nuys Medical Science Building, 635 Barnhill Drive, MS224, Indianapolis, IN 46202-5I 20, USA

Tel + | 31798838||

$\mathrm{Fax}+13179883976$

Email ipetrach@iupui.edu
Abstract: Alpha-1-antitrypsin deficiency (AATD), also known as alpha1-proteinase inhibitor deficiency, is an autosomal co-dominant condition. The genotypes associated with AATD include null, deficient, and dysfunctional alpha-1-antitrypsin (A1AT) variants, which result in low levels of circulating functional A1AT, unbalanced protease activity, and an increased risk of developing lung emphysema, the leading cause of morbidity in these patients. Furthermore, the most common abnormal genotype, $\mathrm{Pi}^{*} \mathrm{ZZ}$ may also cause trapping of abnormally folded protein polymers in hepatocytes causing liver dysfunction. A major focus of therapy for patients with lung disease due to AATD is to correct the A1AT deficiency state by augmenting serum levels with intravenous infusions of human plasma-derived A1AT. This strategy has been associated with effective elevations of A1AT levels and function in serum and lung epithelial fluid and observational studies suggest that it may lead to attenuation in lung function decline, particularly in patients with moderate impairment of lung function. In addition, an observational study suggests that augmentation therapy is associated with a reduction of mortality in subjects with AATD and moderate to severe lung impairment. More recent randomized placebo-controlled studies utilizing computer scan densitometry suggest that this therapy attenuates lung tissue loss. Augmentation therapy has a relative paucity of side effects, but it is highly expensive. Therefore, this therapy is recommended for patients with AATD who have a high-risk A1AT genotype with plasma A1AT below protective levels $(11 \mu \mathrm{M})$ and evidence of obstructive lung disease. In this article, we review the published evidence of A1AT augmentation therapy efficacy, side effects, and safety profile.

Keywords: alpha-1 antitrypsin, COPD, intravenous augmentation therapy

\section{Introduction}

\section{Definition}

Alpha-1-antitrypsin deficiency (AATD) is a hereditary autosomal co-dominant condition, which occurs from the inheritance of two protease inhibitor deficiency alleles of the alpha-1-antitrypsin (A1AT) gene. The A1AT gene, also known as alpha1-proteinase inhibitor gene, PI or SERPINA1, spans $12.2 \mathrm{~kb}$ on the human chromosome 14q31-32.3 and encodes a 52-kD single-chain glycoprotein composed of 394 amino acid residues and three asparagine-linked complex carbohydrate side chains. Hepatocytes are the primary source of A1AT, but other cells including mononuclear phagocytes and lining epithelial cells of the intestinal and respiratory tract, also synthesize this protein. A1AT's main function is serine proteinase inhibition. Neutrophil elastase, a $29-\mathrm{kD}$ extracellular endopeptidase is the preferred target for A1AT, which baits the proteinase at its active site forming a stable 1:1 equimolar complex, which is then cleared from the circulation. ${ }^{1}$ 


\section{Prevalence}

The AATD prevalence data indicate variable distribution around the globe, being highest in northwestern Europe, reaching 1:1,600 in Sweden. ${ }^{2}$ In the US, where the Z genes frequencies are highest in individuals of northern and western European descent, ${ }^{3}$ prevalence estimates range from 1:2,857 to $1: 5,097.4,5$

\section{Abnormal AIAT genotypes}

$\mathrm{A} 1 \mathrm{AT}$ is a highly pleomorphic protein, reflecting a polymorphic gene locus with approximately 100 alleles identified to date. Genotype variants are classified according to the protease inhibitor (PI) isoelectric focusing electrophoretic mobility and to the plasma level and function of A1AT. The normal variant includes the common $\mathrm{M}$ types, present in $95 \%$ of Caucasian individuals with normal A1 AT plasma levels $(>20 \mu \mathrm{mol} / \mathrm{L})$. The deficiency variants include the more common $\mathrm{Z}$ and $\mathrm{S}$ variants found predominantly in the Mediterranean region as well as the rare "M-like" or "S-like" types. These variants are caused by a single amino acid mutation and are usually associated with plasma A1AT levels $<20 \mu \mathrm{mol} / \mathrm{L}$. The rare "null" variant is associated with undetectable A1AT levels. The dysfunctional forms are characterized by normal circulating levels of a functionally impaired A1AT. ${ }^{6}$

\section{Pathogenesis of lung and liver disease in AATD}

The decrease in levels of circulating functional A1AT renders organs such as the lung susceptible to the unopposed action of activated neutrophil elastase released from inflammatory cells. The disrupted homeostasis between protease-antiproteases is further augmented by cigarette smoking, which is associated with excessive elastase activity, degradation of elastin in the lung parenchyma, and ultimately development of the chronic obstructive pulmonary disease (COPD), emphysema. Approximately $60 \%$ of individuals with AATD develop COPD, suggesting that AATD alone is usually not sufficient to cause emphysema, cigarette smoking being a major pathogenic co-factor in these individuals. Recent studies have shown that in addition to the classical protease-antiprotease imbalance in AATD, there are several other mechanisms implicated in the pathogenesis of lung disease in susceptible individuals. Oxidants in cigarette smoke have been shown to oxidize methionine residues within the A1AT active site and weaken its antiprotease function. ${ }^{7}$ Similarly, the mutant Z A1AT, which has a high propensity for forming polymers, inhibits neutrophil elastase at a slower rate than M A1AT.
Furthermore, these polymers exert chemotactic activities, ${ }^{8}$ augmenting the neutrophil elastase burden and perhaps explaining why individuals with AATD have a larger number of neutrophils in the lung parenchyma compared to normal individuals. ${ }^{9}$ In addition, in recent years there was increasing evidence of serpins interacting with enzymes such as cathepsins ${ }^{10,11}$ or caspases ${ }^{12}$ which uncovered unexpected cytoprotective $^{13,14}$ and antimicrobial ${ }^{15-17}$ roles to this class of molecules. Examples of noncanonical effects of A1AT, which we recently summarized, ${ }^{18}$ include intracellular uptake and inhibition of apoptosis of pulmonary vascular endothelial cells, ${ }^{12,13,19}$ direct anti-inflammatory effects on immune ${ }^{20,21}$ and lung vascular cells, ${ }^{22}$ and effects on alveolar and epithelial lung fluid volume regulation. ${ }^{23,24}$ Impairment of these protective mechanisms in AATD may contribute to the pathogenesis of lung disease in AATD and may, in the future, expand the scope and indications of A1AT augmentation therapy.

In contrast to the pathogenesis of lung disease, the liver involvement in AATD is likely due to the trapping and accumulation of Z A1AT polymers inside hepatocytes. Indeed, individuals carrying the A1AT null genotype lack liver involvement. In the case of the $\mathrm{Pi}^{*} \mathrm{Z}, \mathrm{Pi}^{*} \mathrm{~S}$, or other unstable mutations of A1AT, the abnormally folded protein accumulates in the endoplasmic reticulum, leading to liver injury, which may culminate in cirrhosis or hepatocellular carcinoma in some patients. ${ }^{25}$ Many AATD individuals with $\mathrm{Pi}^{*} \mathrm{Z}$ remain protected from this gain-of-toxic function though a protective autophagic disposal of abnormal proteins. ${ }^{26}$

\section{Clinical manifestations}

Although most individuals with AATD remain asymptomatic, the most common clinical manifestation of this condition is COPD, which develops especially in those exposed to cigarette smoking. COPD occurs predominantly in the 3 rd -4 th decade of life and manifests predominantly as emphysema, chronic bronchitis, or bronchiectasis, with symptoms such as dyspnea, cough, wheezing, inability to exercise, fatigue, and frequent respiratory infections. ${ }^{27}$ The diagnosis is supported by pulmonary function tests which may reveal airflow obstruction (with decreased forced expiratory volume in one second $\left[\mathrm{FEV}_{1}\right]$ and $\mathrm{FEV}_{1}$ /forced vital capacity $[\mathrm{FVC}]$ ratio) and impaired gas exchange. Radiologic examination of the lungs by computer tomography (CT) shows decreased attenuation of lung tissue with a predominant basal distribution and a panlobular pattern, along with variable degrees of bronchial wall thickening and dilatation. The lung involvement may 
progress to respiratory failure and death. Since the majority of subjects with AATD and lung disease have a history of tobacco use and their clinical presentation may be undistinguishable from non-AATD-related COPD, ${ }^{28}$ current guidelines recommend AATD testing for all individuals diagnosed with COPD. ${ }^{29}$ The liver is the second most common organ involved in AATD, in approximately $10 \%$ of individuals with this condition. Liver disease occurs predominantly in children but also long-term survivors of AATD, manifesting as jaundice and hepatomegaly, which in rare cases may progress to hepatic cirrhosis and hepatocellular carcinoma. Very infrequent but nevertheless intriguing manifestations of AATD are vasculitis ${ }^{30}$ and the indurated painful skin rash of necrotizing panniculitis. ${ }^{31}$

\section{General treatment considerations for AATD}

In addition to consideration of A1AT augmentation therapy, the overall approach to treating individuals with lung disease from AATD follows the general principles that apply to treating COPD of any etiology, ${ }^{29}$ including the use of bronchodilators and inhaled steroids. ${ }^{32}$ In general, bronchodilators may provide symptomatic improvement even in the absence of a documented bronchodilator effect on pulmonary function tests. Antibiotics should be provided early for COPD exacerbations and long-term oxygen therapy should be instituted when indicated. In addition, subjects with AATD and emphysema may experience depression and anxiety, conditions that should be appropriately addressed and treated. Not in the least, subjects with AATD and COPD may have significant benefits from participating in disease management programs. ${ }^{33}$

\section{AI AT augmentation therapy for AATD}

The major goal of the A1AT augmentation therapy in the treatment of patients with AATD and lung disease is to elevate levels of A1AT in plasma and lung interstitium and correct the deficiency state, with the rationale that adequate A1AT levels may prevent further lung destruction and halt disease progression. ${ }^{29}$ A1AT augmentation therapy has no role in the liver disease due to AATD, as the etiology is related to ineffective secretion of A1AT from hepatocytes. If these patients develop severe hepatic insufficiency and cirrhosis, consideration should be made for orthotopic liver transplantation.

The approaches to providing A1AT augmentation therapy include systemic delivery of A1AT by intravenous or inhalational routes. The intravenous route uses human plasma-derived purified preparations and is currently the US Food and Drug Administration (FDA)-approved form of therapy. The inhalational route, which has been tested with both human plasma-derived and recombinant A1AT preparations remains experimental. ${ }^{10,34}$ Still in experimental stages are several genetic approaches of A1AT augmentation, recently detailed in an excellent review by McLean and colleagues. ${ }^{35}$ Other methods to increase circulating A1AT have been described, aimed at enhancing endogenous A1AT production and/or secretion with hormonal derivatives such as danazol or tamoxifen. ${ }^{36,37}$ The following discussion will focus on intravenous A1AT protein augmentation approach since it is the only approved form of therapy currently available.

\section{Biological efficacy of augmentation therapy}

An effective A1AT augmentation intervention is defined by biochemical and clinical criteria. ${ }^{38}$ To fulfill the biochemical criteria of efficacy, there should be evidence that intravenous augmentation therapy raises A1AT serum levels above the protective threshold and does so over the entire inter-dose interval, coupled with evidence that the functional capacity of infused pooled human plasma A1AT to oppose neutrophil elastase is preserved after its administration. These criteria were met by weekly infusions of purified human A1AT $\left(60 \mathrm{mg} / \mathrm{kg}\right.$ ), which kept serum A1AT levels above $11 \mu \mathrm{M} .{ }^{39}$ This dosing regimen increased local A1AT levels in the lungs, documented by a $60 \%$ to $70 \%$ elevation in the antineutrophil elastase capacity of the epithelial lining fluid obtained via bronchoalveolar lavage..$^{39}$ The serum threshold used in this study was derived from epidemiological studies that associate levels below $50 \mathrm{mg} / \mathrm{dl}(11 \mu \mathrm{M})$ with an increased risk of emphysema, levels of $50-80 \mathrm{mg} / \mathrm{dl}$ with an uncertain risk, and levels above $80 \mathrm{mg} / \mathrm{dl}$ with no risk of lung disease. Furthermore, the weekly dosing of $60 \mathrm{mg} / \mathrm{kg}$ was chosen based on the serum half life of A1AT, its estimated volume of distribution, and prior infusion experiences..$^{40}$ To date, this dosing protocol and A1AT threshold remain the recommended goals of intravenous A1AT augmentation therapy. ${ }^{29}$

In order to gauge the efficacy of A1AT augmentation therapy, in addition to antielastase activity of the airway lining fluid, there is an active research effort to identify other biomarkers which would be pertinent to the lung involvement in AATD. The pathogenesis of lung function decline in COPD in general and AATD in particular is complex and involves increased matrix proteolysis and destruction of lung units. Gottlieb and colleagues measured the effect of 
exogenous A1AT (60 mg/kg once a week for eight weeks) on urine desmosine, a marker of lung matrix degradation, in 12 subjects with AATD (serum A1AT of $17-69 \mathrm{mg} / \mathrm{dl}$ ). ${ }^{41}$ During treatment, the mean urinary excretion of desmosine remained unchanged from its high baseline levels $(p=0.85)$, suggesting that elastin degradation was not dependent upon neutrophil elastase at this stage of the disease, at least in this small group of subjects. Similar results were obtained in a study comparing two different commercial preparations of A1AT, in which neither preparation lead to a statistically significant decrease in urine desmosine excretion at 12 weeks, compared to levels obtained prior to the start of augmentation therapy. ${ }^{42}$ Further studies are needed to increase our insight on how A1AT affects the pathogenesis of COPD, especially in light of the discovery of noncanonical functions of this protein.

\section{Clinical efficacy of augmentation therapy: Observational studies}

Although the strongest evidence of clinical efficacy of any form of therapy is gained through randomized, placebocontrolled studies, execution of such studies in AATD individuals has been faced with multiple challenges, including ethical dilemmas of placebo use and difficulty to enroll a sufficient number of subjects. Therefore, most of the initial clinical efficacy studies of augmentation therapy had relied on nonrandomized prospective observational approaches that included as a main outcome the changes in lung function decline measured by spirometry (ie, rate of $\mathrm{FEV}_{1}$ decline over time) (Table 1).

The earliest study by Seersholm and colleagues in $1997^{38}$ was a prospective controlled, nonrandomized trial comparing 198 German subjects with AATD who were treated with a weekly A1AT dose of $60 \mathrm{mg} / \mathrm{kg}$ IV versus 97 Dutch subjects with AATD patients who received no A1AT infusions. All patients were ex-smokers, with PI ZZ genotype, A1AT plasma levels below $11 \mu \mathrm{M}$ and lung emphysema. After 4.5 years of follow-up, there was a statistically significant slower decline in lung function in the treated group compared with the untreated group (decline in $\mathrm{FEV}_{1}=53 \mathrm{ml} /$ year versus $75 \mathrm{ml} /$ year, respectively, $\mathrm{p}=0.02$ ). Stratification by initial lung function showed an effect of treatment primarily for patients with an $\mathrm{FEV}_{1}=31 \%-65 \%$ predicted, the range of a moderate obstructive ventilator defect. ${ }^{38}$ Therefore, the study indicated that augmentation therapy may slow the disease progression in patients with moderately reduced lung function due to AATD.

The largest prospective cohort study in the USA was conducted by the National Heart Lung and Blood Institute (NHLBI) AATD Registry Group, which analyzed data from individuals with severe AATD in $1998 .{ }^{43}$ The study included 1129 subjects, and analyzed data from 927 subjects, of which 277 were untreated versus 650 treated with A1AT augmentation therapy (of those, 389 were always treated and 261 were only partly treated). All subjects were 18 years or older and had A1AT levels $<11 \mu \mathrm{mol} / \mathrm{L}$. Over a follow-up period of 3.5 years, subjects receiving A1AT augmentation therapy had a lower mortality rate compared to the untreated group (risk ratio $[R R]=0.64,95 \%[C I]: 0.43-0.94 ; p=0.02$ ), particularly in subjects with $\mathrm{FEV}_{1}<50 \%$ predicted. Overall there was no statistically significant difference in the decline in $\mathrm{FEV}_{1}$ between the treated and the untreated group, but in patients with moderate airflow obstruction (mean $\mathrm{FEV}_{1}=35 \%-49 \%$ predicted) the decline in lung function was significantly slower for subjects receiving augmentation therapy (mean difference $=27 \mathrm{ml} /$ year, 95\% CI: 3-51 ml/year; $\mathrm{p}=0.03$ ). The main limitations of this study were that the decision to treat was left to the primary treating physician and the A1AT dosing regimens varied among treated subjects.

A third study investigated the rate of lung function decline before and after the initiation of A1AT augmentation in a cohort of 96 German patients with AATD. ${ }^{44}$

Table I Comparison of changes in FEV, decline in prospective observational studies of augmentation therapy

\begin{tabular}{|c|c|c|c|c|c|c|c|}
\hline \multirow[t]{2}{*}{ Study } & \multicolumn{3}{|c|}{ Overall changes in FEV, decline } & \multicolumn{4}{|c|}{ Changes in FEV, decline in specific subgroups } \\
\hline & $\begin{array}{l}\text { With } \\
\text { augmentation }\end{array}$ & $\begin{array}{l}\text { Without } \\
\text { augmentation }\end{array}$ & $\mathbf{P}$ & Initial FEV, & $\begin{array}{l}\text { With } \\
\text { augmentation }\end{array}$ & $\begin{array}{l}\text { Without } \\
\text { augmentation }\end{array}$ & $\mathbf{P}$ \\
\hline Seersholm and colleagues ${ }^{32}$ & $53 \mathrm{ml} / \mathrm{yr}$ & $75 \mathrm{ml} / \mathrm{yr}$ & 0.02 & $31 \%-65 \%$ & $62 \mathrm{ml} / \mathrm{yr}$ & $83 \mathrm{ml} / \mathrm{yr}$ & 0.04 \\
\hline NHLB| $\left.\right|^{35}$ & $5 \mathrm{l} \mathrm{ml} / \mathrm{yr}$ & $56 \mathrm{ml} / \mathrm{yr}$ & NS & $35 \%-49 \%$ & $66.4 \mathrm{ml} / \mathrm{yr}$ & $93.2 \mathrm{ml} / \mathrm{yr}$ & 0.03 \\
\hline \multirow[t]{2}{*}{ Wencker and colleagues ${ }^{36}$} & $34.2 \mathrm{ml} / \mathrm{yr}$ & $49.2 \mathrm{ml} / \mathrm{yr}$ & 0.019 & $30 \%-65 \%$ & $37.8 \mathrm{ml} / \mathrm{yr}$ & $49.3 \mathrm{ml} / \mathrm{yr}$ & NS \\
\hline & & & & $>65 \%$ & $48.9 \mathrm{ml} / \mathrm{yr}$ & $122.5 \mathrm{ml} / \mathrm{yr}$ & 0.001 \\
\hline Chapman and colleagues ${ }^{37}$ & $30 \mathrm{ml} / \mathrm{yr}$ & $63 \mathrm{ml} / \mathrm{yr}$ & 0.019 & NS & & & \\
\hline
\end{tabular}

Abbreviations: $\mathrm{FEV}$, forced expiratory volume in one second; NS, not significant. 
The group included subjects with A1AT levels $<35 \%$ of normal, regardless of phenotype and moderate obstructive lung disease $\left(\mathrm{FEV}_{1}<65 \%\right.$ predicted). In addition, subjects with accelerated lung function decline $\left(\mathrm{FEV}_{1}\right.$ decline rate $>120 \mathrm{ml} /$ year) were included, regardless of baseline $\mathrm{FEV}_{1}$. The study showed that the decline in $\mathrm{FEV}_{1}$ was significantly slower during the treatment period compared to the pre-treatment period (34.3 $\mathrm{ml} /$ year versus $49.2 \mathrm{ml} /$ year, respectively; $p=0.019)$. A subset analysis showed that augmentation therapy was particularly effective in patients with baseline $\mathrm{FEV}_{1}>65 \%$ predicted (mean difference $73.6 \mathrm{ml} /$ year; $\mathrm{p}=0.045$ ), and in seven individuals who exhibited a rapid decline in $\mathrm{FEV}_{1}$ before beginning augmentation therapy $(256 \mathrm{ml} / \mathrm{yr}$ versus $53 \mathrm{ml} /$ year; $\mathrm{p}=0.001)$. There was also a trend for a statistical significant $(\mathrm{p}=0.066)$ effect of augmentation therapy in slowing the rate of $\mathrm{FEV}_{1}$ decline in patients with moderate airflow obstruction at baseline $\left(\mathrm{FEV}_{1}\right.$ $30 \%-65 \%$ predicted).

Finally, a retrospective observational study using data collected by the Canadian AIR Registry, compared 21 subjects receiving augmentation therapy versus 42 matched controls, followed for 5.6 years. The results of this study, reported as an abstract, suggested a slower decline in $\mathrm{FEV}_{1}$ in patients receiving augmentation therapy compared with the subjects who did not $(29.9 \mathrm{ml} / \mathrm{yr}$ versus $63.6 \mathrm{ml} /$ year; $\mathrm{p}=0.019) .{ }^{45}$

Together, all these observational studies strongly suggest that A1AT augmentation therapy slows the decline in lung function in subjects with A1AT and lung disease, particularly in those with a moderate severity of airflow obstruction.

\section{Clinical efficacy of augmentation therapy: Randomized studies}

The observational studies discussed above provided useful information for the design of subsequent prospective placebocontrolled studies. For example, using the rate of FEV decline as the primary outcome and based on the NHLBI Registry study data, to detect a difference in $\mathrm{FEV}_{1}$ decline of $23 \mathrm{ml} / \mathrm{yr}$ (ie, a 28\% reduction), a study would require an enrollment of 147 subjects per treatment arm, with an initial $\mathrm{FEV}_{1}$ of $35 \%$ to $49 \%$ predicted, and who will undergo biannual spirometry measurements over a four-year period. ${ }^{46}$ Similarly, a study to detect a $40 \%$ reduction in mortality over a five-year period would require 342 subjects per treatment arm. ${ }^{46}$ Furthermore, there are other major challenges in conducting such trials, including the caveat of $\mathrm{FEV}_{1}$ use as main outcome in COPD trials, criticized due to its poor correlation with the extent of emphysema and other important outcomes such as health-related quality of life $;{ }^{47}$ the variable rate of lung disease progression; and the often delayed clinical diagnosis of individuals with AATD. ${ }^{28,44}$

A more recent method in COPD research is the use of CT scanning to assess lung density, an outcome which strongly correlates with quantitative pathology scores of emphysema and is more sensitive to detect progression of emphysema compared to traditional lung function parameters. ${ }^{48}$ Dirksen and colleagues reported the first double blind, randomized placebo-controlled trial of A1AT augmentation therapy, using both $\mathrm{FEV}_{1}$ and $\mathrm{CT}$-measured lung densitometry as outcomes. ${ }^{49}$ They compared the effect of $250 \mathrm{mg} / \mathrm{kg}$ of A1AT against $625 \mathrm{mg} / \mathrm{kg}$ of albumin administered at four week intervals for at least three years in 56 patients with AATD and moderate obstructive ventilatory defect $\left(\mathrm{FEV}_{1} 30 \%-80 \%\right.$ predicted). Admittedly underpowered for both outcomes, no differences were noted in the $\mathrm{FEV}_{1}$ decline, but there was a trend for a reduction in the loss of lung tissue in the group who received A1AT augmentation therapy compared to the placebo group $(1.5 \pm 0.41 \mathrm{~g} / \mathrm{L} /$ year versus $2.6 \pm 0.41 \mathrm{~g} / \mathrm{L} /$ year (mean $\pm \mathrm{SEM})$, respectively $(\mathrm{p}=0.07) .{ }^{49}$

A more recent European trial (The EXAcerbations and CT scan as Lung Endpoints [EXACTLE] trial) further explored the use of CT densitometry for the assessment of a conventional regimen of augmentation therapy in subjects with AATD and lung disease. The study included 77 patients with AATD and PiZ who were randomized to receive either A1AT augmentation therapy (60 mg/kg IV weekly) or placebo for $2-2.5$ years. ${ }^{50}$ Similarly to their previous trial, the patients who received A1AT had a trend towards lesser decline in lung density measurements (Table 2). This trial also supports the notion that CT densitometry may be more sensitive in detecting changes in response to treatment compared to other functional and subjective parameters in subjects with emphysema and AATD.$^{50}$ Indeed, a higher powered multinational randomized placebo-controlled trial is utilizing CT densitometry as primary outcome of A1AT augmentation therapy in AATD (clinicaltrials.gov \# NCT00261833).

\section{Augmentation therapy: Effect on exacerbations}

The effect of A1AT augmentation therapy on airway inflammatory markers was evaluated by Stockley and colleagues in 12 subjects with AATD and Pi Z before and following A1AT augmentation therapy $(60 \mathrm{mg} / \mathrm{kg}$ weekly for four weeks). ${ }^{51}$ Augmentation therapy led to a rise of AAT concentration in sputum similar to that of nondeficient subjects. Furthermore, A1AT augmentation was associated with a favorable change in the sputum inflammatory milieu, 
Table 2 Changes in emphysema progression assessed by computed tomography densitometry in placebo-controlled studies of augmentation therapy

\begin{tabular}{|c|c|c|c|c|c|c|c|}
\hline \multirow[t]{2}{*}{ Study } & \multirow[t]{2}{*}{ Design } & \multirow[t]{2}{*}{$\mathbf{N}$} & \multirow[t]{2}{*}{$\begin{array}{l}\text { Augmentation } \\
\text { therapy }\end{array}$} & \multirow[t]{2}{*}{ Placebo } & \multicolumn{2}{|c|}{$\begin{array}{l}\text { Estimated treatment differences } \\
\text { (augmentation-placebo) }\end{array}$} & \multirow[t]{2}{*}{ P value } \\
\hline & & & & & Method & $\begin{array}{l}\text { Result } \\
\text { (g/L/year) }\end{array}$ & \\
\hline Dirksen I ${ }^{43}$ & $\begin{array}{l}\text { Double-blind, } \\
\text { randomized } \\
\text { placebo-controlled } \\
\text { (two centers) }\end{array}$ & 56 & $\begin{array}{l}250 \mathrm{mg} / \mathrm{kg} \text { IV Every four } \\
\text { weeks for three years }\end{array}$ & Albumin $(625 \mathrm{mg} / \mathrm{kg})$ & $\begin{array}{l}\text { I5th percentile } \\
\text { lung density (PDI5) } \\
\text { adjusted for lung } \\
\text { volume }(\mathrm{g} / \mathrm{L})\end{array}$ & $\begin{array}{l}8.9 \\
(2.6-11.5)\end{array}$ & 0.07 \\
\hline \multirow[t]{4}{*}{$\begin{array}{l}\text { Dirksen } 2 \\
(\text { EXACTLE) }\end{array}$} & $\begin{array}{l}\text { Double-blind, } \\
\text { randomized } \\
\text { placebo-controlled } \\
\text { (three centers) }\end{array}$ & 77 & $\begin{array}{l}60 \mathrm{mg} / \mathrm{kg} \text { IV Every week } \\
\text { For 2-2.5 years }\end{array}$ & albumin $(2 \%)$ & $\begin{array}{l}\text { Method la } \\
\text { (physiological, slope } \\
\text { analysis) }\end{array}$ & $\begin{array}{l}0.857 \\
(-0.065-1.778)\end{array}$ & 0.068 \\
\hline & & & & & $\begin{array}{l}\text { Method } 2 \text { (statistical, } \\
\text { slope analysis) }\end{array}$ & $\begin{array}{l}0.700 \\
(-0.028-1.427)\end{array}$ & 0.059 \\
\hline & & & & & $\begin{array}{l}\text { Method } 3 \\
\text { (physiological, } \\
\text { end-point analysis) }\end{array}$ & $\begin{array}{l}1.596 \\
(-0.220-3.412)\end{array}$ & 0.084 \\
\hline & & & & & $\begin{array}{l}\text { Method } 4 \text { (statistical, } \\
\text { end-point analysis) }\end{array}$ & $\begin{array}{l}1.472 \\
(0.009-2.935)\end{array}$ & 0.049 \\
\hline
\end{tabular}

Notes: ${ }^{a}$ Analyzed I5th percentile lung density (density value at which $15 \%$ of the pixels have lower densities) using two methods of adjustment for lung volume variability (physiological and statistical) and two statistical approaches (slope analysis and end-point analysis).

with statistical significant reductions in sputum elastase activity and levels of the chemoattractant leukotriene B4, and a trend towards decreased sputum myeloperoxidase and interleukin-8.

In addition to decreasing airway inflammation, other endpoints of efficacy of augmentation therapy investigated in the setting of respiratory exacerbations were the rate of airway microbial colonization and the frequency of acute COPD exacerbations in AATD. Lieberman and colleagues conducted a patient survey to document the self-reported sense of personal benefit from augmentation therapy. ${ }^{52}$ Of the adult patients with $\mathrm{Pi} Z \mathrm{ZZ}$ genotype interrogated by a webbased questionnaire, there were 96 patients who reported treatment with A1AT for one year or more and 47 responders who reported not receiving such treatment. Seventy-four of 89 patients who had received infusions for longer than one year believed they had definitely benefited from such therapy, approximately half of them attributing it to a reduction in the number of infectious COPD exacerbations, from a reported average of five episodes to less than one episode annually $(\mathrm{p}<0.001)$. Other prospective studies have shown that such acute exacerbations in subjects with AATD are common ${ }^{53}$ even with the use of augmentation therapy. ${ }^{28,54}$ The recently reported EXACTLE trial did not show an effect of A1AT augmentation therapy on the number of COPD exacerbations compared to placebo, but showed that augmentation therapy decreased the severity of such acute exacerbations. ${ }^{50}$ This effect which may have a positive impact on health-related quality of life, health care utilization, and disease progression attributed to reductions in neutrophil elastase burden.

\section{AI AT augmentation treatment recommendations}

A1AT augmentation therapy is recommended for individuals with abnormal A1AT genotypes who have A1AT levels below the protective threshold of $11 \mu \mathrm{M}$ and have evidence of airflow obstruction. ${ }^{29}$ Since weekly infusions of AAT at $60 \mathrm{mg} / \mathrm{kg}$ are effective in restoring plasma AAT concentrations to protective levels and restoring the epithelial lung fluid's antielastase properties throughout the dosing interval, regulatory agencies and guidelines have thus recommended this schedule and dosing for the treatment of affected individuals. $^{29}$

\section{Dosage and frequency considerations}

Since augmentation therapy is expensive, it is imperative to optimize its utilization, particularly since costs have not decreased despite the advent of more suppliers on the market in recent years. Considerations for optimal dosage and infusion schedules include patient's comfort and acceptance, as well total treatment costs. In fact, the recommended regimen of $60 \mathrm{mg} / \mathrm{kg}$ once a week has not been widely adopted. In the 
NHLBI study, $25.3 \%$ of participants received biweekly and $21.8 \%$ received monthly infusions at the beginning of the study with additional patients switching to non-weekly regimens during the study period. ${ }^{55}$ In a more recent study of 922 patients, $32.4 \%$ received infusions every two weeks and $7.6 \%$ received monthly infusions. ${ }^{54}$

Initial studies addressing the biological efficacy of non-weekly regimens suggested that there was only partial coverage throughout the dosing interval. For example, in nine subjects who received A1AT at $250 \mathrm{mg} / \mathrm{kg}$ every 28 days, serum AAT levels as well the antielastase activity in epithelial lining fluid were in the protective range for "at least" 25 days after the infusion. ${ }^{56}$ In another study, a regimen of $120 \mathrm{mg} / \mathrm{kg}$ every two weeks studied in 23 patients could not maintain nadir serum levels above $70 \mathrm{mg} / \mathrm{dl}$ for the entire 14-day dosing interval in most and did not correlate with adequate antielastase activity in epithelial lining fluid assessed by bronchoscopy. ${ }^{57}$ However, studies directly comparing clinical outcomes with these nonweekly regimens are not available and in the NHLBI study it was observed that the initial frequency of therapy was not associated with differences in survival. ${ }^{55}$

\section{Pharmacokinetic considerations}

A high level of variability in trough serum A1AT levels in response to dosing has been observed in several studies, raising the concept that targeted pharmacokinetic studies may lead to the design of individualized dosing regimens. In the first of these studies, daily A1AT levels were followed in five patients after receiving a dose of $120 \mathrm{mg} / \mathrm{kg}$ of A1AT and were used to calculate individual dosage schemes with a computer simulation using a two-compartment pharmacokinetic model. ${ }^{58}$ The authors estimated that a dose of $1-2 \mathrm{~g}$ every two weeks should be enough to maintain trough A1AT levels above the protective threshold in most individuals, a dose markedly lower than the recommended $60 \mathrm{mg} / \mathrm{kg} /$ week. In another study, Monte Carlo simulations based on population pharmacokinetic concepts applied to A1AT levels measured after weekly, bi-weekly, tri-weekly, and monthly dosage regimens, showed that intervals between infusions longer than one week are possible in most patients while maintaining an appropriate level of serum AAT above the protective threshold $(50 \mathrm{mg} / \mathrm{dl}) .{ }^{59}$ In this study, the authors proposed that a tri-compartment model is more suitable for exogenous AAT administration and suggested that weekly doses of $50 \mathrm{mg} / \mathrm{kg}$ or bi-weekly doses of $120 \mathrm{mg} / \mathrm{kg}$ confer protective trough levels at least $85 \%$ of the time, while a monthly regimen is not suitable, as it protected for only 22 of the 28 days. In a more recent study, Zamora and colleagues evaluated seven patients initially receiving $180 \mathrm{mg} / \mathrm{kg}$ of AAT every three weeks, and used A1AT levels measured after 7,14 , and 21 days to readjust dose and frequency based on a one-compartment model. ${ }^{60}$ The authors concluded that the mean optimized final A1AT dose was $123.1 \mathrm{mg} / \mathrm{kg}$ every two weeks (range 118.5-125.6) for a desired AAT serum trough of $0.50 \mathrm{~g} / \mathrm{L}$. Surprisingly, results differed when two different commercial preparations were compared.

In all studies, the once-a-week regimen showed adequate protective levels throughout the infusion interval, and this has been the regimen studied in most clinical trials including the recent randomized studies. The factors associated with increased clearance of A1AT have not been defined. Independent variables such as sex, age, and body weight have no influence on pharmacokinetic parameters. ${ }^{60}$ Although these studies suggest that less expensive and more convenient individualized regimens can be designed, caution should be employed, since clinical outcome studies using these personalized regimens are not available. If a nonweekly regimen is chosen to treat an individual patient, it would be prudent to periodically follow trough A1AT levels to ensure adequate protection.

\section{Augmentation treatment for heterozygous individuals}

Studies have shown that PI*MZ individuals may have a small increase in lung function decline $(25 \mathrm{ml} / \mathrm{yr} \text { versus } 21 \mathrm{ml} / \mathrm{yr})^{61}$ and may have a slightly higher risk for developing COPD (odds ratio 2.3$)^{62}$ compared to PI*MM individuals. It is likely that some $\mathrm{PI} * \mathrm{MZ}$ individuals may have a particularly high risk for COPD, however early identification of this subgroup is rarely possible. As mentioned before, current augmentation therapy strategies aim at increasing A1AT levels above a protective threshold, usually lower than what is observed in carriers of abnormal A1AT alleles, particularly PI*MZ individuals. Given the complete absence of any data suggesting efficacy for heterozygous individuals, current recommendations do not endorse use of augmentation therapy for such individuals. ${ }^{63}$ Individuals with PI*SZ genotypes may have A1AT levels $<11 \mu \mathrm{M}$; in such cases, augmentation therapy may be advisable if lung function impairment is present.

\section{Safety of intravenous AI AT augmentation therapy}

The experience of thousands of individuals treated with A1AT augmentation therapy suggests that it is generally safe. The few side effects reported were generally mild and rarely 
required major interventions or interruption of therapy. Two major registry studies provide data from large number of patients from both Europe and the US.

Wencker and colleagues reported the side effects associated with augmentation therapy $(60 \mathrm{mg} / \mathrm{kg}$ IV once a week) in 443 patients with severe AATD and emphysema from the German registry recruited between 1989 and $1995 .{ }^{64}$ Between 1989 and 1995, a total of 58,000 infusions were administered which only triggered 124 side effects reported in 65 patients. In the majority of these patients the observed adverse reactions were typical of intravenous infusions of proteins, such as fever or chills (in 17 patients), urticaria (18), nausea or vomiting (21), and fatigue (7). Increased dyspnea of unclear etiology was reported by 17 patients and was thought to be related to the absolute protein load in the infusion. Three patients terminated the treatment permanently because of repeated symptoms of fevers or chills immediately after each infusion from different batches on more than one occasion. There were five severe side effects reported during the study that required medical intervention or hospitalizations. Four patients suffered anaphylactic reaction and one patient developed congestive heart failure exacerbation, all eventually experiencing complete recovery. No deaths or viral transmission related to A1AT augmentation therapy was observed during the study period.

In the US, the most comprehensive report or side effects following A1AT augmentation therapy was published by Stoller and colleagues using the NHLBI Registry data. ${ }^{65}$ Patients included were divided into "always, sometimes, and never receiving therapy". For all participants and all severity categories, the absolute frequency of adverse events was very low ( $95 \%$ CI: 0.019 to 0.023 events per patient-month), and interestingly, there was no change over time in the percentage of participants reporting an adverse reaction. A total of 720 side effects were reported, the most common ones being headache (47\%), dizziness (17\%), nausea $(9 \%)$, and dyspnea $(9 \%)$, the latter being classified as severe. No transmission of viral hepatitis, HIV infection, or prion disease was reported. Participants receiving weekly treatments did report a higher rate of total adverse events ( 0.030 events per patient-month) than those being treated every two to three weeks $(0.024$ events per patient-month; $\mathrm{p}=0.020)$ or monthly (0.005 events per patient-month; $\mathrm{p}<0.001)$. Furthermore, those treated weekly also reported statistically significant higher rates of severe and moderate adverse events, while subjects who received infusions every two to three weeks reported milder adverse effects than the other groups. Careful examination of the side effects reported from the German registry compared to the US registry suggests there were more cases of anaphylactic reactions in the European study (four patients versus none, respectively), while side effects requiring medical attention such as emergency room visit, hospitalization, or physician office visit were more common among American patients ( $1 \%$ versus $6 \%$, respectively). These differences may be due to recall bias (as the side effects in both studies were recorded at various time intervals), the exclusion of events related to recalled flawed lots (due to the sucrose component in one instance and presence of a pyrogen in the other), as well as the variable frequency of augmentation therapy in the latter study. A rare case of IgE-mediated anaphylactic reaction following the third intravenous infusion of A1AT has been reported. ${ }^{66}$

\section{Alphal-proteinase inhibitor preparations}

There are currently three FDA-approved preparations of A1AT purified from human plasma commercially available in the US: Aralast NP (initially named Respitin and marketed as Aralast by Baxter Healthcare; Deerfield, IL, USA), Prolastin (Talecris Biotherapeutics, Research Triangle Park, NC, USA) and Zemaira ${ }^{\circledR}$ (CSL Behring, King of Prussia, PA, USA). All these products are available as lyophilized preparations. A liquid preparation (Respira, Kamada Ltd., Israel) as well as a purified formulation of Prolastin are planned for future release.

Few studies have compared the effectiveness and safety between these formulations, with studies showing that Aralast ${ }^{42}$ and Zemaira ${ }^{\circledR 67}$ have biochemical equivalence to their comparator, Prolastin. One internally funded pilot study from the maker of Zemaira ${ }^{\circledR}$ (Bioanalytical Laboratory, Technical Operations, ZLB Behring LLC, Kankakee, IL, USA) suggested a higher purity of their product compared to Prolastin and Aralast. ${ }^{68}$

\section{Cost effectiveness of intravenous augmentation therapy}

A1AT augmentation therapy is expensive, with an average annual total health care cost ranging from $\$ 36,471$ to $\$ 46,114$, and a median ranging from $\$ 12,485$ to $\$ 37,100.69,70$ The cost and cost-effectiveness of A1AT augmentation therapy (Table 3 ) is generally analyzed as the cost per lifeyear saved (CLYS) for treated individuals, which is the ratio of the change in expected net COPD medical cost resulting from A1AT replacement therapy relative to the change in years of life saved through the intervention. Utilizing this method, an initial cost-effectiveness estimation based 
Table 3 Comparison of cost-effectiveness analyses of AIAT augmentation therapy

\begin{tabular}{|c|c|c|c|c|c|}
\hline Study & Year & Location & Method & Results & Conclusions \\
\hline Hay and colleagues ${ }^{32}$ & |99| & US & CLYS & $\begin{array}{l}C Y L S=\$ 28,000-\$ 72,000 \text { for } \\
70 \% \text { efficacy. CYLS }=\$ 50,000 \\
\text { and } \$ 128,000 \text { for } 30 \% \text { efficacy }\end{array}$ & $\begin{array}{l}\text { Therapy would need to } \\
\text { improve survival by } 30 \%-50 \% \\
\text { to be cost effective }\end{array}$ \\
\hline Alkins and O'Malley ${ }^{72}$ & 2000 & $\begin{array}{l}\text { US AATD } \\
\text { NHLBI } \\
\text { registry }\end{array}$ & DEALE & $\begin{array}{l}C Y L S=\$ 10,747 \text { to } \$ 53,735 \\
\text { for } 55 \% \text { efficacy }\end{array}$ & $\begin{array}{l}\text { Cost effective in those } \\
\text { with emphysema and lung } \\
\text { dysfunction }\end{array}$ \\
\hline Gildea and colleagues ${ }^{73}$ & 2003 & $\begin{array}{l}\text { US AATD } \\
\text { NHLBI } \\
\text { registry }\end{array}$ & Markov & $\begin{array}{l}\text { ICER }=\$ 207,84 \mathrm{I} / \mathrm{QALY} \text { for } \\
\text { treatment up to } \mathrm{FEV},<35 \% \\
\text { predicted } \\
\mathrm{ICER}=\$ 3 \mathrm{I} 2,5 \mathrm{I} \text { I/QALY for } \\
\text { treatment for life }\end{array}$ & $\begin{array}{l}\text { Cost should be reduced to } \\
\$ 4,900 \text { for therapy to be } \\
\text { considered cost effective }\end{array}$ \\
\hline
\end{tabular}

Abbreviations: AIAT, alpha-I antitrypsin; AATD, alpha-I antitrypsin deficiency; CYLS, cost per year of life saved; DEALE, declining exponential approximation of life expectancy; FEV , forced expiratory volume in one second; ICER, incremental cost-effectiveness ratios; NHLBI, National Heart Lung and Blood Institute; QALY, quality-adjusted life-year; US, United States.

on available studies before 1991 by Hay and colleagues suggested that to be comparable to widely used medical interventions such as antihypertensives, coronary bypass, and cholesterol-lowering drugs, A1AT augmentation therapy would need to narrow the age- and sex-adjusted survival probability gap between Pi ZZ and normal individuals by at least $30 \%-50 \%{ }^{71}$

Utilizing the declining exponential approximation of life expectancy (DEALE) technique, which assumes constant death rates and an inverse relation between remaining life expectancy and annual death rate, Alkins and O'Malley calculated the incremental cost (the value added to usual care) per year of life saved (CYLS) for A1AT replacement therapy. For a replacement regimen of weekly IV infusions of $60 \mathrm{mg} / \mathrm{kg}$ in a $70-\mathrm{kg}$ subject with severe AATD and an $\mathrm{FEV}_{1}<50 \%$ of predicted, and utilizing mortality data from the NHLBI Registry, the CYLS was $\$ 13,971$. Based on this study, it was suggested that A1AT augmentation therapy was cost-effective in patients with AATD and emphysema with a significant degree of lung dysfunction. ${ }^{72}$ These studies indicated the cost-effectiveness ratio for A1AT augmentation therapy was in a similar range with that of hemodialysis.

A re-examination of the cost-effectiveness of A1AT augmentation therapy using a model of disease progression also based on data from the NHLBI registry was reported by Gildea and colleagues. ${ }^{73}$ The authors used a Markov-based decision analytic module and assessed three different strategies: (1) no augmentation therapy for individuals with AATD; (2) A1AT augmentation therapy for life for AATD individuals who have indication for such therapy; and (3) A1AT augmentation therapy for AATD individuals who have indication for such therapy but only until their lung function deteriorates to a $\mathrm{FEV}_{1}$ below $35 \%$ of predicted. A hypothetical cohort of 30,000 identical individuals was evaluated for each strategy using Monte Carlo simulation. Costs were adjusted to the 2001 US dollar, and effectiveness was adjusted by quality-adjusted life year (QALY). Compared to the individuals with AATD and lung disease receiving no augmentation therapy, which would incur a \$92,091 cost with 4.62 QALYs, the model of the AATD individual receiving augmentation treatment for life cost $\$ 895,243$ yielding 7.19 QALYs, while the ones receiving augmentation only until $\mathrm{FEV}_{1}$ falls below 35\% had a predicted cost of $\$ 511,930$ and produced 6.64 QALYs. Therefore, the incremental cost-effectiveness ratio (ICER) was $\$ 207,841 /$ QALY for an A1AT augmentation therapy until $\mathrm{FEV}_{1}<35 \%$ predicted and \$312,511/QALY for A1AT augmentation therapy for life. It was concluded that the annual cost of A1AT augmentation therapy would have to be reduced from $\$ 54,765$ to $\$ 4,900$ for the augmentation therapy for the life strategy to be considered cost-effective. Given the lack of alternative treatments, this study further emphasized the need to discover both clinically effective and cost-effective therapies for individuals with AATD and lung disease.

\section{Future considerations A I AT augmentation therapy} via aerosol inhalation

The vast area available for gas exchange in the lung has long been recognized as an attractive route of systemic drug delivery. ${ }^{74}$ Small studies have demonstrated that aerosolized 
A1AT delivery led to significant elevations of A1AT above protective levels in both plasma and the epithelial lining fluid, ${ }^{75}$ which may be translated into sustained antielastase protection with once-or twice a day inhalation. In patients with AATD and relatively mild lung function impairment, adequate deposition of A1AT in the lung periphery appears to be achievable using the inhalation route. ${ }^{76}$ This attractive form of therapy, likely to prove less costly than intravenous augmentation, is currently under investigation.

\section{Augmentation therapy post lung transplantation}

Lung transplantation is indicated for subjects with AATD and end-stage emphysema. In general, routine post transplant augmentation therapy is not recommended, as no supportive data are available. However, given the detection of significant increases in elastase activity in the lung, as measured in the bronchoalveolar lavage of post-transplant patients during symptomatic respiratory episodes, ${ }^{77}$ many clinicians advocate the use of A1AT augmentation therapy during episodes of lung inflammation, including chronic rejection. ${ }^{78}$

\section{Conclusions}

Current evidence based on prospective observational studies suggests that A1AT intravenous augmentation therapy has a positive impact in attenuating the lung function decline and may decrease mortality in subjects with AATD and moderate airflow obstruction. Newer randomized trials suggest that A1AT augmentation therapy slows emphysema progression and ameliorates the severity of acute disease exacerbations. These effects are supported by biochemical evidence that infused A1AT reaches the epithelial lung fluid and decreases airway inflammation. Experience with intravenous augmentation therapy suggests that it is safe, with few and usually well tolerated side effects. The decision to initiate augmentation therapy in affected individuals with impaired lung function should be based on collective data of efficacy, safety of augmentation therapy, and, currently, lack of alternative interventions.

Adequately powered randomized, placebo-controlled trials, utilizing clinical and biochemical endpoints of efficacy are needed to determine the most effective augmentation regimen and the subgroups of patients who would benefit from it. Other important issues to be addressed include the improvement of the cost effectiveness of therapy, implementation of alternate modalities of A1AT delivery, and further studies to assess the role of augmentation therapy after lung transplantation. New insights from basic science research regarding novel functions of A1AT and additional mechanisms of disease development in AATD, accelerated progress in the translational application of gene therapy and safe drug delivery, together with ongoing efforts of early disease detection, will undoubtedly improve the quality and length of life of individuals with this condition.

\section{Disclosure}

The authors received funds from FAMRI, VA, and NIH-NHLBI (IP) and NIH-NHLBI and the Alpha-1 Foundation (MC). The authors report no conflicts of interest in this work.

\section{References}

1. Perlmutter DH, Joslin G, Nelson P, et al. Endocytosis and degradation of alpha 1-antitrypsin-protease complexes is mediated by the serpin-enzyme complex (SEC) receptor. J Biol Chem. 1990;265(28):16713-16716.

2. Sveger T. alpha 1-antitrypsin deficiency in early childhood. Pediatrics. 1978;62(1):22-25.

3. Hutchison DC. Alpha 1-antitrypsin deficiency in Europe: geographical distribution of Pi types S and Z. Respir Med. 1998;92(3):367-377.

4. O'Brien ML, Buist NR, Murphey WH. Neonatal screening for alpha1antitrypsin deficiency. J Pediatr. 1978;92(6):1006-1010.

5. Silverman EK, Miletich JP, Pierce JA, et al. Alpha1-antitrypsin deficiency. High prevalence in the St. Louis area determined by direct population screening. Am Rev Respir Dis. 1989;140(4):961-966.

6. Okayama H, Brantly M, Holmes M, et al. Characterization of the molecular basis of the alpha 1-antitrypsin F allele. Am J Hum Genet. 1991;48(6):1154-1158.

7. Taggart C, Cervantes-Laurean D, Kim G, et al. Oxidation of either methionine 351 or methionine 358 in alpha 1-antitrypsin causes loss of anti-neutrophil elastase activity. $J$ Biol Chem. 2000;275(35): 27258-27265.

8. Mulgrew AT, Taggart CC, Lawless MW, et al. Z alpha1-antitrypsin polymerizes in the lung and acts as a neutrophil chemoattractant. Chest. 2004;125(5):1952-1957.

9. Mahadeva R, Atkinson C, Li Z, et al. Polymers of Z alpha1-antitrypsin co-localize with neutrophils in emphysematous alveoli and are chemotactic in vivo. Am J Pathol. 2005;166(2):377-386.

10. Geraghty P, Rogan MP, Greene CM, et al. Alpha-1-antitrypsin aerosolised augmentation abrogates neutrophil elastase-induced expression of cathepsin B and matrix metalloprotease 2 in vivo and in vitro. Thorax. 2008;63(7):621-626.

11. Taggart CC, Lowe GJ, Greene CM, et al. Cathepsin BL, and S cleave and inactivate secretory leucoprotease inhibitor. $J$ Biol Chem. 2001;276(36):33345-33352.

12. Petrache I, Fijalkowska I, Medler TR, et al. \{alpha\}-1 Antitrypsin Inhibits Caspase-3 Activity, Preventing Lung Endothelial Cell Apoptosis. Am J Pathol. 2006;169(4):1155-1166.

13. Petrache I, Fijalkowska I, Zhen L, et al. A Novel Anti-apoptotic Role for Alpha-1 Antitrypsin in the Prevention of Pulmonary Emphysema. Am J Respir Crit Care Med. 2006;173(11):1222-1228.

14. Ikebe N, Akaike T, Miyamoto Y, et al. Protective effect of S-nitrosylated alpha(1)-protease inhibitor on hepatic ischemia-reperfusion injury. J Pharmacol Exp Ther. 2000;295(3):904-911.

15. Baranger K, Zani ML, Chandenier J, et al. The antibacterial and antifungal properties of trappin-2 (pre-elafin) do not depend on its protease inhibitory function. FEBS J. 2008;275(9):2008-2020.

16. Doumas S, Kolokotronis A, Stefanopoulos P. Anti-inflammatory and antimicrobial roles of secretory leukocyte protease inhibitor. Infect Immun. 2005;73(3):1271-1274.

17. Williams SE, Brown TI, Roghanian A, et al. SLPI and elafin: one glove, many fingers. Clin Sci (Lond). 2006;110(1):21-35. 
18. Tuder RM, Petrache I. Molecular multitasking in the airspace: alpha1-antitrypsin takes on thrombin and plasmin. Am J Respir Cell Mol Biol. 2007;37(2):130-134.

19. Aldonyte R, Hutchinson ET, Jin B, et al. Endothelial alpha-1-antitrypsin attenuates cigarette smoke induced apoptosis in vitro. COPD. 2008;5(3):153-162.

20. Churg A, Wang X, Wang RD, et al. Alpha1-antitrypsin suppresses TNF-alpha and MMP-12 production by cigarette smoke-stimulated macrophages. Am J Respir Cell Mol Biol. 2007;37(2):144-151.

21. Nita I, Hollander C, Westin U, et al. Prolastin, a pharmaceutical preparation of purified human alpha1-antitrypsin, blocks endotoxin-mediated cytokine release. Respir Res. 2005;6:12.

22. Subramaniyam D, Virtala R, Pawlowski K, et al. TNF-alpha-induced self expression in human lung endothelial cells is inhibited by native and oxidized alpha1-antitrypsin. Int J Biochem Cell Biol. 2008;40(2):258-271.

23. Lazrak A, Nita I, Subramaniyam D, et al. Alpha1-antitrypsin inhibits epithelial $\mathrm{Na}+$ transport in vitro and in vivo. Am J Respir Cell Mol Biol. 2009; Jan 8. [Epub ahead of print]

24. Swystun V, Chen L, Factor P, et al. Apical trypsin increases ion transport and resistance by a phospholipase $\mathrm{C}$-dependent rise of $\mathrm{Ca} 2+. \mathrm{Am} \mathrm{J}$ Physiol Lung Cell Mol Physiol. 2005;288(5):L820-30.

25. Mahadeva R, Chang WS, Dafforn TR, et al. Heteropolymerization of S, I, and Z alpha1-antitrypsin and liver cirrhosis. J Clin Invest. 1999;103(7):999-1006.

26. Perlmutter DH. Autophagic disposal of the aggregation-prone protein that causes liver inflammation and carcinogenesis in alpha-1-antitrypsin deficiency. Cell Death Differ. 2009;16(1):39-45.

27. Ranes J, Stoller JK. A review of alpha-1 antitrypsin deficiency. Semin Respir Crit Care Med. 2005;26(2):154-166.

28. Campos MA, Alazemi S, Zhang G, et al. Clinical characteristics of subjects with symptoms of alpha1-antitrypsin deficiency older than 60 years. Chest. 2009;135(3):600-608.

29. American Thoracic Society/European Respiratory Society Statement: Standards for the diagnosis and management of individuals with alpha-1 antitrypsin deficiency. Am J Respir Crit Care Med. 2003;168(7):818-900.

30. Nowack R, Flores-Suarez LF, van der Woude FJ. New developments in pathogenesis of systemic vasculitis. Curr Opin Rheumatol. 1998;10(1):3-11.

31. Valverde R, Rosales B, Ortiz-de Frutos FJ, et al. Alpha-1-antitrypsin deficiency panniculitis. Dermatol Clin. 2008;26(4):447-451, vi.

32. Wilcke JT, Dirksen A. The effect of inhaled glucocorticosteroids in emphysema due to alpha1-antitrypsin deficiency. Respir Med. 1997;91(5):275-279.

33. Campos MA, Alazemi S, Zhang G, et al. Effects of a disease management program in individuals with alpha-1 antitrypsin deficiency. $C O P D$ 2009;6(1):31-40.

34. Spencer LT, Humphries JE, Brantly ML. Antibody response to aerosolized transgenic human alphal-antitrypsin. $N$ Engl J Med. 2005;352(19):2030-2031.

35. McLean C GC, McElvaney NG. Gene targeted therapeutics for liver diseasein alpha-1 antitrypsin deficiency. Biologics: Targets and Therapy. 2009;3:63-75.

36. Wewers MD, Gadek JE, Keogh BA, et al. Evaluation of danazol therapy for patients with PiZZ alpha-1-antitrypsin deficiency. Am Rev Respir Dis. 1986;134(3):476-480.

37. Wewers MD, Brantly ML, Casolaro MA, et al. Evaluation of tamoxifen as a therapy to augment alpha-1-antitrypsin concentrations in Z homozygous alpha-1-antitrypsin-deficient subjects. Am Rev Respir Dis. 1987;135(2):401-402.

38. Seersholm N, Wencker M, Banik N, et al. Does alpha1-antitrypsin augmentation therapy slow the annual decline in FEV1 in patients with severe hereditary alpha1-antitrypsin deficiency? Wissenschaftliche Arbeitsgemeinschaft zur Therapie von Lungenerkrankungen (WATL) alpha1-AT study group. Eur Respir J. 1997;10(10):2260-2263.

39. Wewers MD, Casolaro MA, Sellers SE, et al. Replacement therapy for alpha 1-antitrypsin deficiency associated with emphysema. $N$ Engl J Med. 1987;316(17):1055-1062.
40. Gadek JE, Klein HG, Holland PV, et al. Replacement therapy of alpha 1-antitrypsin deficiency. Reversal of protease-antiprotease imbalance within the alveolar structures of PiZ subjects. J Clin Invest. 1981;68(5):1158-1165.

41. Gottlieb DJ, Luisetti M, Stone PJ, et al. Short-term supplementation therapy does not affect elastin degradation in severe alpha(1)-antitrypsin deficiency. The American-Italian AATD Study Group. Am J Respir Crit Care Med. 2000;162(6):2069-2072.

42. Stoller JK, Rouhani F, Brantly M, et al. Biochemical efficacy and safety of a new pooled human plasma alpha(1)-antitrypsin, Respitin. Chest. 2002;122(1):66-74.

43. Survival and FEV1 decline in individuals with severe deficiency of alpha1-antitrypsin. The Alpha-1-Antitrypsin Deficiency Registry Study Group. Am J Respir Crit Care Med. 1998;158(1):49-59.

44. Wencker M, Fuhrmann B, Banik N, et al. Longitudinal follow-up of patients with alpha(1)-protease inhibitor deficiency before and during therapy with IV alpha(1)-protease inhibitor. Chest. 2001;119(3):737-744.

45. Chapman KR, Bradi AC, Paterson D, et al. Slower lung function decline during augmentation therapy in patients with alpha-1 antitrypsin deficiency: results from the Canadian AIR Registry. Proc Am Thorac Soc. 2005;2:A808.

46. Schluchter MD, Stoller JK, Barker AF, et al. Feasibility of a clinical trial of augmentation therapy for alpha(1)-antitrypsin deficiency. The Alpha 1-Antitrypsin Deficiency Registry Study Group. Am J Respir Crit Care Med. 2000;161(3 Pt 1):796-801.

47. Cazzola M, MacNee W, Martinez FJ, et al. Outcomes for COPD pharmacological trials: from lung function to biomarkers. Eur Respir J. 2008;31(2):416-469.

48. Stolk J, Putter H, Bakker EM, et al. Progression parameters for emphysema: a clinical investigation. Respir Med. 2007;101(9):1924-1930.

49. Dirksen A, Dijkman JH, Madsen F, et al. A randomized clinical trial of alpha(1)-antitrypsin augmentation therapy. Am J Respir Crit Care Med. 1999;160(5 Pt 1):1468-1472.

50. Dirksen A, Piitulainen E, Parr DG, et al. Exploring the role of CT densitometry: a randomised study of augmentation therapy in alpha-1 antitrypsin deficiency. Eur Respir J. 2009; Feb 5. [Epub ahead of print]

51. Stockley RA, Bayley DL, Unsal I, et al. The effect of augmentation therapy on bronchial inflammation in alpha1-antitrypsin deficiency. Am J Respir Crit Care Med. 2002;165(11):1494-1498.

52. Lieberman J. Augmentation therapy reduces frequency of lung infections in antitrypsin deficiency: a new hypothesis with supporting data. Chest. 2000;118(5):1480-1485.

53. Needham M, Stockley RA. Exacerbations in \{alpha\}1-antitrypsin deficiency. Eur Respir J. 2005;25(6):992-1000.

54. Campos MA, Sandhaus R. Exacerbations of respiratory symptoms in patients with alpha-1 antitrypsin deficiency on augmentation therapy. Am J Respir Crit Care Med. 2004;169(7):A767.

55. Griesenbach U, Chonn A, Cassady R, et al. Comparison between intratracheal and intravenous administration of liposome-DNA complexes for cystic fibrosis lung gene therapy. Gene Ther. 1998;5(2):181-188.

56. Hubbard RC, Sellers S, Czerski D, et al. Biochemical efficacy and safety of monthly augmentation therapy for alpha 1-antitrypsin deficiency. JAMA. 1988;260(9):1259-1264.

57. Barker AF, Iwata-Morgan I, Oveson L, et al. Pharmacokinetic study of alpha1-antitrypsin infusion in alpha1-antitrypsin deficiency. Chest. 1997;112(3):607-613.

58. Piitulainen E, Bernspang E, Bjorkman S, et al. Tailored pharmacokinetic dosing allows self-administration and reduces the cost of IV augmentation therapy with human alpha(1)-antitrypsin. Eur J Clin Pharmacol. 2003;59(2):151-156.

59. Soy D, de la Roza C, Lara B, et al. Alpha-1-antitrypsin deficiency: optimal therapeutic regimen based on population pharmacokinetics. Thorax. 2006;61(12):1059-1064.

60. Zamora NP, Pla RV, Del Rio PG, et al. Intravenous human plasmaderived augmentation therapy in alpha 1-antitrypsin deficiency: from pharmacokinetic analysis to individualizing therapy. Ann Pharmacother. 2008;42(5):640-646. 
61. Dahl M, Tybjaerg-Hansen A, Lange P, et al. Change in lung function and morbidity from chronic obstructive pulmonary disease in alpha1antitrypsin MZ heterozygotes: A longitudinal study of the general population. Ann Intern Med. 2002;136(4):270-279.

62. Hersh CP, Dahl M, Ly NP, et al. Chronic obstructive pulmonary disease in alpha1-antitrypsin PI MZ heterozygotes: a meta-analysis. Thorax. 2004;59(10):843-849.

63. Sandhaus RA, Turino G, Stocks J, et al. alpha1-Antitrypsin augmentation therapy for PI*MZ heterozygotes: a cautionary note. Chest. 2008;134(4):831-834.

64. Wencker M, Banik N, Buhl R, et al. Long-term treatment of alpha1antitrypsin deficiency-related pulmonary emphysema with human alpha1-antitrypsin. Wissenschaftliche Arbeitsgemeinschaft zur Therapie von Lungenerkrankungen (WATL)-alpha1-AT-study group. Eur Respir J. 1998;11(2):428-433.

65. Stoller JK, Fallat R, Schluchter MD, et al. Augmentation therapy with alpha1-antitrypsin: patterns of use and adverse events. Chest. 2003;123(5):1425-1434.

66. Meyer FJ, Wencker M, Teschler $\mathrm{H}$, et al. Acute allergic reaction and demonstration of specific IgE antibodies against alpha-1-protease inhibitor. Eur Respir J. 1998;12(4):996-997.

67. Stocks JM, Brantly M, Pollock D, et al. Multi-center study: the biochemical efficacy, safety and tolerability of a new alpha1-proteinase inhibitor, Zemaira. COPD. 2006;3(1):17-23.

68. Cowden DI, Fisher GE, Weeks RL. A pilot study comparing the purity, functionality and isoform composition of alpha-1-proteinase inhibitor (human) products. Curr Med Res Opin. 2005;21(6):877-883.
69. Mullins CD, Wang J, Stoller JK. Major components of the direct medical costs of alpha1-antitrypsin deficiency. Chest. 2003;124(3): 826-831.

70. Mullins CD, Huang X, Merchant S, et al. The direct medical costs of alpha(1)-antitrypsin deficiency. Chest. 2001;119(3):745-752.

71. Hay JW, Robin ED. Cost-effectiveness of alpha-1 antitrypsin replacement therapy in treatment of congenital chronic obstructive pulmonary disease. Am J Public Health. 1991;81(4):427-433.

72. Alkins SA, O'Malley P. Should health-care systems pay for replacement therapy in patients with alpha(1)-antitrypsin deficiency? A critical review and cost-effectiveness analysis. Chest. 2000;117(3):875-880.

73. Gildea TR, Shermock KM, Singer ME, et al. Cost-effectiveness analysis of augmentation therapy for severe alpha1-antitrypsin deficiency. Am J Respir Crit Care Med. 2003;167(10):1387-1392.

74. Patton JS, Byron PR. Inhaling medicines: delivering drugs to the body through the lungs. Nat Rev Drug Discov. 2007;6(1):67-74.

75. Hubbard RC, Crystal RG. Strategies for aerosol therapy of alpha 1-antitrypsin deficiency by the aerosol route. Lung. 1990;168 Suppl: 565-578.

76. Vogelmeier C, Kirlath I, Warrington S, et al. The intrapulmonary half-life and safety of aerosolized alpha1-protease inhibitor in normal volunteers. Am J Respir Crit Care Med. 1997;155(2):536-541.

77. King MB, Campbell EJ, Gray BH, et al. The proteinase-antiproteinase balance in alpha-1-proteinase inhibitor-deficient lung transplant recipients. Am J Respir Crit Care Med. 1994;149(4 Pt 1):966-971.

78. Trulock EP. Lung transplantation for alpha 1-antitrypsin deficiency emphysema. Chest. 1996;110(6 Suppl):284S-294S.
Biologics: Targets \& Therapy

\section{Publish your work in this journal}

Biologics: Targets \& Therapy is an international, peer-reviewed journal focusing on the patho-physiological rationale for and clinical application of Biologic agents in the management of autoimmune diseases, cancers or other pathologies where a molecular target can be identified. This journal is indexed on PubMed Central, CAS,

\section{Dovepress}

EMBase, Scopus and the Elsevier Bibliographic databases. The manuscript management system is completely online and includes a very quick and fair peer-review system, which is all easy to use. Visit http://www.dovepress.com/testimonials.php to read real quotes from published authors. 